\title{
Prevalence and Risk Factors of Asthma among Adolescents and Their Parents in Al-Ain (United Arab Emirates)
}

\author{
Shirina Alsowaidi ${ }^{a}$ Abdishakur Abdulle $^{a}$ Roos Bernsen ${ }^{b}$ \\ Departments of ${ }^{a}$ Internal Medicine and ${ }^{b}$ Community Medicine, Faculty of Medicine and Health Sciences, \\ United Arab Emirates University, Al-Ain, United Arab Emirates
}

\section{Key Words}

Adolescent asthma $\cdot$ Asthma $\cdot$ Bedouins $\cdot$ Prevalence, asthma $\cdot$ United Arab Emirates

\begin{abstract}
Background: Evidence indicates that the prevalence of asthma tends to increase in the developed world. However, little is known about current prevalence rates and risk factors of asthma in countries in transition, e.g. the United Arab Emirates (UAE). Objectives: We investigated the prevalence of asthma and its independent risk factors among adolescents and adults in Al-Ain, UAE. Methods: For a two-stage, randomly selected survey, 10,000 questionnaires were distributed to adolescents and their parents. Logistic regression was applied to assess asthma prevalence and independent associations with age, gender, education, nationality and family history. Results: In total, 6,543 subjects were included in the final analysis. Median age was 30 years (range: 8-93 years); $53 \%$ were male. The overall self-reported prevalence of asthma was $13 \%$. Direct standardization with the UAE population as the reference yielded a prevalence of $12 \%$. Logistic regression revealed family history and UAE nationality (about $50 \%$ of nationals were of Bedouin origin) as the main
\end{abstract}

risk factors for asthma, and a significant $(p=0.001)$ interaction between gender and age: in the group aged 13-19 years, males had a significantly higher prevalence of asthma [17 and 14\%; adjusted odds ratio (OR): 1.45; 95\% confidence interval (Cl): 1.10-1.90]; in the group aged $>19$ years, males had a significantly lower prevalence of asthma (11 and 13\%; adjusted OR: $0.77 ; 95 \% \mathrm{Cl}$ : 0.60-0.95) than females. Conclusions: The prevalence of asthma is comparable to findings of earlier studies. The higher prevalence in adolescent males compared to females may possibly be due to sex-specific lifestyle factors. Strong predictors of asthma such as family history and UAE nationality may indicate modernization and possible genetic susceptibility, warranting further studies in this population.

Copyright $\odot 2009$ S. Karger AG, Basel

\section{Introduction}

Asthma, a chronic inflammatory disorder, has recently been the focus of a significant number of studies in various geographical regions and societies worldwide. Results from international studies increase our understanding on the epidemiology of asthma and related al-

\section{KARGER}

Fax +4161306 1234 E-Mail karger@karger.ch www.karger.com (c) 2009 S. Karger AG, Basel

0025-7931/10/0792-0105\$26.00/0

Accessible online at:

www.karger.com/res
Shirina Alsowaidi, MD, FRCP

Department of Internal Medicine

Faculty of Medicine and Health Sciences

POB 17666, UAE University, Al-Ain (United Arab Emirates)

Tel. +971 3713 7339, Fax +971 3767 2995, E-Mail shirina.alsowaidi@uaeu.ac.ae 
lergic diseases $[1,2]$. These data have shown not only some significant discrepancies in the prevalence of asth$\mathrm{ma}$, but also variations in asthma-related risk factors including exposure to cigarette smoke, obesity, family history, urbanization, allergic sensitization and vitamin D deficiency [3-10].

Although environmental and genetic susceptibility to allergic diseases may be important [11, 12], large geographical variations in disease prevalence between peoples of similar genetic background and the trend to increasing incidence rates of allergic diseases worldwide may not be fully explained by these factors [13]. The overwhelming majority of what is known about the increasing prevalence of asthma and other allergic diseases are results from studies carried out in Western countries, whereas from Arabian Gulf countries, such as the United Arab Emirates (UAE), data are scarce.

Since the discovery of vast oil reserves $\sim 30$ years ago, there has been an impressive economic and social transformation in the UAE [14]. As a result, most of the abovementioned risk factors are highly prevalent due to rapid changes in lifestyle, the increase in wealth and modernization and substantial environmental changes (i.e. increased exposure to pollen due to anti-desertification projects). So far, family history and sensitization to housedust mites, pollen and other airborne allergens [15-17] have been identified as possible risk factors for asthma. Interestingly, a high prevalence of vitamin D deficiency in women, reportedly related to asthma in offspring [18, 19], has also been found among Emirati women of childbearing age [20].

A study in schoolchildren in the UAE (1994) found the prevalence of asthma to be $13.6 \%$ [21]. In 2000, other investigators in the UAE reported a similar prevalence of about $14 \%$ among school children $6-13$ years of age [22], but data on adolescent groups and adults in this country are lacking.

We therefore initiated this study with a relatively large sample size to document the current prevalence of asthma and to identify independent risk factors among school-age adolescents and their parents in Al-Ain city, UAE.

\section{Patients and Methods}

The Ethics Review Committee of the Faculty of Medicine and Health Sciences, UAE University, approved the study protocols and all subjects (adults and parents of children) gave informed consent.
Subjects and Data Collection

We carried out an epidemiological survey using a questionnaire from the International Study of Asthma and Allergies in Childhood (ISAAC). Apart from the ISAAC questions on allergic rhinitis and asthma, there were questions on demographic data, medication use (salbutamol and oral/inhaled steroids) and family history of asthma ('Does anyone of your family have asthma?').

In line with the ISAAC protocols [23], schools were considered as the sampling units. Our schools are situated in the oasis city of Al-Ain with a population of approximately 500,000 inhabitants.

A multistage random sampling method was used: first we randomly selected 10 secondary schools from a list of all secondary schools in Al-Ain, then we selected at random from all classes an equal number of students in such a way that the total number of students selected from a particular school was proportionate to the total number of students in that school. In this way, a total of about 10,000 questionnaires were distributed in 69 classes. Each child was asked to take the questionnaires home to be filled out with the help of a parent/guardian. Also, the children were asked to deliver two copies of the questionnaire to their parents or one or two other siblings depending on how many parents were available. Therefore, this study included male/female high-school children aged 13-19 years and their parents or other siblings. In case a participating family member was illiterate, the questionnaire had to be filled out with the help of a relative who could read and write.

Demographic data (gender, age and nationality), education and clinical history of asthma and rhinitis (nasal blockage, rhinorrhea, sneezing and irritation) were recorded. In each school, at least one school nurse was assigned by the school administration, on a voluntary basis, to collate the filled questionnaires for onward handover to the research team, and subsequently data were entered into computers by trained research assistants. All questionnaires were eventually completed between November 2007 and January 2008.

\section{Definition of Asthma}

The definition of asthma used in this study was: having had wheezing in the past 12 months or ever had asthma.

\section{Statistical Analysis}

We assessed the prevalence of asthma and computed an age-/ sex-standardized prevalence (direct standardization) with the total UAE population as the reference population (Census 2005) if the age/sex distribution of the study population differed markedly from that of the total UAE population. In patients with asthma (according to our definition), we assessed the prevalence of symptoms and asthma-related variables in the past 12 months: wheeze, sleep disturbed by wheeze, speech limited by wheeze, wheeze following exercise, dry night cough and ever use of salbutamol or steroids (oral or inhaled). We used univariate logistic regression to assess the crude association of asthma with age in the two study groups (13-19 and >19 years), gender, education, nationality and parental asthma (or family history of asthma, as applicable). We assessed the independent relationship of asthma with the aforementioned risk factors by means of logistic regression (the model was assessed stepwise with the backward Wald method). The final model was tested with the multilevel structure (levels: school, family and family members) of the data taken into 
Table 1. Characteristics of the study participants, all and stratified for age group

\begin{tabular}{|c|c|c|c|}
\hline Variable & $\begin{array}{l}\text { All } \\
(n=6,543)\end{array}$ & $\begin{array}{l}\text { Age } 13-19 \\
(n=2,802)\end{array}$ & $\begin{array}{l}\text { Age }>19 \\
(n=3,733)\end{array}$ \\
\hline \multicolumn{4}{|l|}{ Age } \\
\hline$<13$ years & $8(0)$ & $0(0)$ & $0(0)$ \\
\hline $13-19$ years & $2,802(43)$ & $2,802(100)$ & $0(0)$ \\
\hline$>19$ years & $3,733(57)$ & $0(0)$ & $3,733(100)$ \\
\hline Median (range) & $30(8-93)$ & $16(13-19)$ & $42(20-93)$ \\
\hline \multicolumn{4}{|l|}{ Gender } \\
\hline Male & $3,434(52)$ & $1,415(51)$ & $2,015(54)$ \\
\hline Female & $3,109(48)$ & $1,387(49)$ & $1,718(46)$ \\
\hline \multicolumn{4}{|l|}{ Nationality } \\
\hline UAE & $3,158(48)$ & $1,459(52)$ & $1,696(45)$ \\
\hline Other Arabs & $2,490(38)$ & $1,024(37)$ & $1,461(39)$ \\
\hline Other & $863(13)$ & $310(11)$ & $553(15)$ \\
\hline Missing ${ }^{\mathrm{a}}$ & $32(1)$ & $9(0)$ & $23(1)$ \\
\hline \multicolumn{4}{|l|}{ Education } \\
\hline Illiterate/primary & $881(14)$ & $29(1)$ & $848(23)$ \\
\hline Elementary & $1,258(19)$ & $788(28)$ & $467(13)$ \\
\hline Secondary & $2,865(44)$ & $1,869(67)$ & $995(27)$ \\
\hline $\begin{array}{l}\text { University/ } \\
\text { postgraduate }\end{array}$ & $1,381(21)$ & $80(3)$ & $1,301(35)$ \\
\hline Missing & $158(2)$ & $36(1)$ & $122(3)$ \\
\hline \multicolumn{4}{|l|}{ Family history } \\
\hline No & $3,563(55)$ & $1,402(50)$ & $2,156(58)$ \\
\hline Yes & $1,634(25)$ & $727(26)$ & $905(24)$ \\
\hline Missing $^{\mathrm{a}}$ & $1,246(20)$ & $673(24)$ & $672(18)$ \\
\hline
\end{tabular}

Numbers (\%) of participants are listed.

a Some subjects did not answer this question.

account. Subjects with missing values were excluded from the multivariate model. $\mathrm{p} \leq 0.05$ was considered significant. SPSS (version 15) was used for all analyses except for multilevel logistic regression, which was performed with Stata (version 10.0).

\section{Results}

In total, about 10,000 subjects (children and their parents) were invited to participate. Of these, 7,550 (response rate: $76 \%)$ returned the completed questionnaire. However, only 6,543 samples were included in the final analysis due to unreported age or inconsistently reported age (e.g. mothers of index subjects reporting an age of 12 years) in about $13 \%$ of the subjects. The median age was 30 years (range $8-93$ years); $53 \%$ were males. The characteristics of the study population are shown in table 1. Overall self-reported prevalence of asthma was $13 \%$. The age/sex distribution of the study population differed from

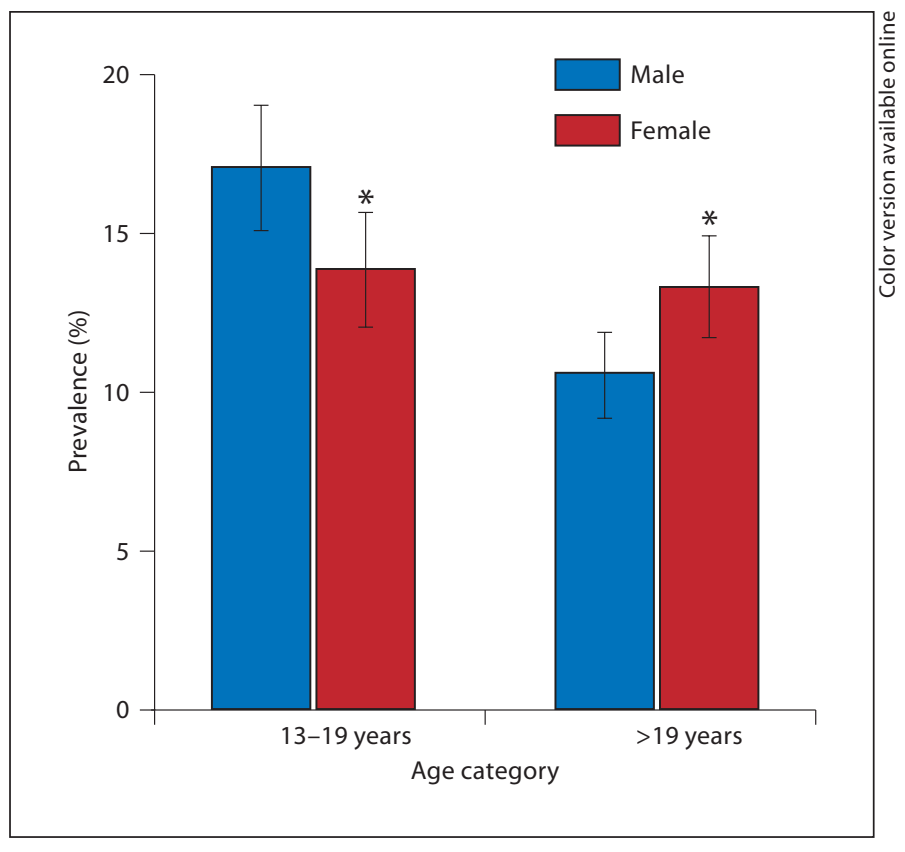

Fig. 1. Prevalence of asthma by age and gender. ${ }^{*} \mathrm{p}=0.01$, males vs. females. Error bars denote 95\% CI.

that of the UAE population (mainly the adolescent group was overrepresented). The age-/sex-standardized prevalence was $12 \%$. The prevalence of asthma with $95 \%$ confidence intervals (CI) for different age/sex groups is illustrated in figure 1 . The prevalence of several asthma-related variables in asthma patients shows that $16 \%$ of patients had mild asthma (mild symptoms and episodes of wheezing in the past 12 months) while $44 \%$ had moderate asthma (sometimes a disturbed sleep due to wheezing; table 2).

Univariate logistic regression showed no significant difference in prevalence between males $(13 \%)$ and females $(14 \% ; p=0.73)$. However, multivariate logistic regression showed a significant interaction $(\mathrm{p}=0.001)$ between gender and age. This means that the association between gender and asthma was different for different age groups. We therefore repeated the multivariate analysis for the two age groups separately. The prevalence of asthma in the group aged 13-19 years was $16 \%$, while that in the adult group ( $>19$ years of age) was $12 \%$. Asthma prevalence for subgroups, crude odds ratios (OR) and adjusted ORs with $95 \%$ CI for both age groups are listed in table 3. In this table, results of logistic regression are presented for variables selected in the final model only. In both age groups, a family history of asthma was the stron- 
Table 2. Prevalence of symptoms and asthma-related variables in all asthma patients $(\mathrm{n}=873)$ and patients stratified for age

\begin{tabular}{|c|c|c|c|}
\hline Variable & $\begin{array}{l}\text { All } \\
(\mathrm{n}=873)\end{array}$ & $\begin{array}{l}\text { Age } 13-19 \\
(n=433)\end{array}$ & $\begin{array}{l}\text { Age }>19 \\
(n=440)\end{array}$ \\
\hline Current wheeze & $419(48)$ & $190(44)$ & $229(52)$ \\
\hline$\geq 4$ wheeze attacks ${ }^{\mathrm{a}, \mathrm{b}}$ & $141(16)$ & $63(15)$ & $79(18)$ \\
\hline Sleep disturbed ${ }^{\mathrm{a}, \mathrm{b}}$ & $388(44)$ & $177(41)$ & $214(49)$ \\
\hline Speech limited ${ }^{\mathrm{a}, \mathrm{b}}$ & $252(29)$ & $130(30)$ & $122(28)$ \\
\hline Wheeze after exercise $e^{a, b}$ & $290(33)$ & $154(36)$ & $135(31)$ \\
\hline Dry night cough ${ }^{\mathrm{a}, \mathrm{c}}$ & $428(49)$ & $207(48)$ & $219(50)$ \\
\hline Ever use of salbutamol ${ }^{\mathrm{d}}$ & $204(23)$ & $91(21)$ & $112(26)$ \\
\hline \multicolumn{4}{|l|}{ Ever use of steroids } \\
\hline$(\text { oral or inhaled) })^{\mathrm{e}}$ & $93(11)$ & $40(9)$ & $53(12)$ \\
\hline
\end{tabular}

Numbers (\%) of asthma patients are listed.

${ }^{a}$ In the past 12 months

$\mathrm{b}$ These questions (part of the ISAAC questionnaire) were only to be answered by participants reporting wheeze in the past 12 months.

${ }^{\mathrm{c}}$ The prevalence in the total group of non-asthma subjects was $11 \%$.

$\mathrm{d}$ The prevalence in the total group of non-asthma subjects was $1 \%$.

e The prevalence in the total group of non-asthma subjects was $2 \%$.

gest predictor of asthma with an OR of 3.75 (95\% CI: $2.66-5.28)$ in the adolescents and an OR of 5.84 (95\% CI: 4.63-7.37) in the adults. In the group aged 13-19 years, Arabs other than UAE nationals appeared to be at lower risk than UAE nationals (OR $=0.67,95 \%$ CI: 0.49-0.91; the majority of the non-national group originated from other Arab countries). In this younger age group, males significantly more often reported asthma (17 vs. $14 \%$ in females, $\mathrm{OR}=1.45,95 \% \mathrm{CI}: 1.10-1.90$ ), while in the age group $>19$ years males reported significantly less asthma than females ( 11 vs. $13 \%$, respectively, OR $=0.75,95 \% \mathrm{CI}$ : $0.60-0.95)$. The adjusted results presented here are from multilevel analysis. The models not taking the multilevel structure into account yielded similar adjusted results (not shown).

\section{Discussion}

The present study reported an overall prevalence of asthma of $13 \%$ among adolescents and adults in Al-Ain, an oasis city in the UAE. The population of the UAE has, according to the 2005 census, only about $20 \%$ nationals. A UAE nationality does not necessarily mean that a sub- ject is originally from indigenous UAE origin since some immigrants from other Arab countries were naturalized during the first decades of the state of the UAE. However, from the subjects' family names we were able to estimate that about $50 \%$ of those who indicated a UAE nationality were from Bedouin origin. Our overall prevalence was similar to that in previous studies [21,22]; however, these previous studies were conducted in younger children (613 years). Therefore, we cannot compare the previously found prevalence with ours, also because in elderly people current wheeze (which is part of our asthma definition) is possibly not associated with asthma, but chronic obstructive pulmonary disease. In another study performed in Oman [24], a neighboring country of the UAE, a prevalence of $20 \%$ was found in older children (13-14 years), being about twice as high as that in younger children in their study. Comparing this result with our data, our prevalence of $16 \%$ in the group aged 13-19 years seems low. A possible explanation for this difference could be our lower response rate (75\% compared to the Omani response rate of about $90 \%$ ), but only if participation in our study is dependent on having asthma. However, if participation is dependent on asthma status, one would expect an overrepresentation of asthmatic subjects, rather than an underrepresentation. This would result in an overestimate of the real prevalence and would also result in a higher prevalence than the one found in the Oman study (with its higher response rate). Another, more plausible explanation for the higher prevalence in the Omani study is that the Omani sample included relatively fewer non-nationals, who have, similarly to our study, shown a lower prevalence of asthma. Indeed, the prevalence of asthma in nationals aged 13-19 years was $19 \%$ in our study, being close to their prevalence of $20 \%$.

We dichotomized age into age $\leq 19$ years and age $>19$ years given that in adults asthma is usually associated with other factors than in adolescents. Although the age group $>19$ years comprised a large range, the prevalence of asthma did not vary significantly (data not shown); only in the small group $(n=35)$ aged $\geq 70$ years, it was relatively high (37\%). In these elderly groups, the underlying mechanism of wheeze is probably increasingly associated with chronic obstructive pulmonary disease rather than asthma.

Our finding of a significantly higher prevalence in male than in female adolescents is not in agreement with findings in this age group in other studies [25], where the pattern is found to be different (a female-to-male prevalence of at least 50:50) from that in primary school children. Higher exposure of males to outdoor allergens may 
Table 3. Independent risk factors for asthma

\begin{tabular}{|c|c|c|c|c|c|}
\hline & $\begin{array}{l}\text { Asthma } \\
\%\end{array}$ & $\begin{array}{l}\text { OR } \\
\text { crude }\end{array}$ & $\begin{array}{l}\text { OR } \\
\text { adjusted }^{2}\end{array}$ & $\begin{array}{l}95 \% \mathrm{CI} \\
\text { adjusted }\end{array}$ & $\begin{array}{l}\mathrm{p} \text { value } \\
\text { adjusted }\end{array}$ \\
\hline \multicolumn{6}{|c|}{ Age group $13-19$ years $(n=2,802)^{1}$} \\
\hline \multicolumn{6}{|l|}{ Nationality } \\
\hline UAE (reference) & 19 & 1 & 1 & & \\
\hline Other Arabs & 12 & 0.58 & 0.67 & $0.49-0.91$ & 0.01 \\
\hline Other & 11 & 0.55 & 0.65 & $0.41-1.03$ & 0.07 \\
\hline \multicolumn{6}{|l|}{ Gender } \\
\hline Female (reference) & 14 & 1 & 1 & & \\
\hline Male & 17 & 1.28 & 1.45 & $1.10-1.90$ & 0.008 \\
\hline \multicolumn{6}{|l|}{ Family history of asthma } \\
\hline No (reference) & 9 & 1 & 1 & & \\
\hline Yes & 27 & 3.63 & 3.75 & $2.66-5.28$ & 0.0005 \\
\hline \multicolumn{6}{|l|}{ Education $^{3}$} \\
\hline Illiterate/primary school & 14 & 0.75 & & & \\
\hline Elementary school & 18 & 1.03 & & & \\
\hline Secondary school & 14 & 0.79 & & & \\
\hline University+ (reference) & 18 & 1 & & & \\
\hline \multicolumn{6}{|c|}{ Age group $>19$ years $(n=3,733)^{4}$} \\
\hline \multicolumn{6}{|c|}{ Gender } \\
\hline Female (reference) & 13 & 1 & 1 & - & - \\
\hline Male & 11 & 0.77 & 0.75 & $0.60-0.95$ & 0.02 \\
\hline \multicolumn{6}{|l|}{ Family history of asthma } \\
\hline No (reference) & 6 & 1 & 1 & - & - \\
\hline Yes & 27 & 5.88 & 5.84 & $4.63-7.37$ & 0.0005 \\
\hline \multicolumn{6}{|l|}{ Nationality ${ }^{3}$} \\
\hline UAE & 14 & 1 & & & \\
\hline Other Arabs & 11 & 0.7 & & & \\
\hline Other & 8 & 0.6 & & & \\
\hline \multicolumn{6}{|l|}{ Education $^{3}$} \\
\hline Illiterate/primary school & 14 & 1.13 & & & \\
\hline Elementary school & 11 & 0.88 & & & \\
\hline Secondary school & 10 & 0.77 & & & \\
\hline University+ (reference) & 13 & 1 & & & \\
\hline \multicolumn{6}{|c|}{${ }^{1}$ Due to missing values, only 2,120 subjects were included in this model. } \\
\hline \multirow{2}{*}{\multicolumn{6}{|c|}{ ORs are results of multilevel logistic regression and are adjusted for all other variables in the model. }} \\
\hline${ }^{3}$ This variable was not se & & & & & \\
\hline \multicolumn{6}{|l|}{ odds ratios are presented. } \\
\hline${ }^{4}$ Due to missing values, & subiec & lude & odel. & & \\
\hline
\end{tabular}

partially explain these findings because male adolescents in the UAE tend to spend most of their time either in school or in the neighborhood, as opposed to their less outgoing and often more culturally oriented female counterparts. Selective participation might be another explanation, since the usually less motivated males (compared to females) in this age group may have been more easily persuaded to participate when they have asthma themselves. This explanation would suggest that we may have overestimated the real prevalence. Other sources of selection bias that we checked for were: (1) 13\% of questionnaires had to be excluded due to inconsistently reported age (this has caused a slight overestimation of the prevalence, since the prevalence of asthma in the excluded group was $11 \%$, compared to $13 \%$ in the group used for analysis), and (2) the age/sex distribution of our study subjects differed from that in the general UAE population due to the study design (index subjects were adolescents 
and this group was overrepresented). However, the age-/ sex-standardized prevalence was only slightly lower than our initial estimate.

Summarizing these limitations, we conclude that we may have overestimated the prevalence of asthma. For example, our finding of a higher risk in adolescent boys (compared to their female peers) may possibly be explained by selection bias.

In adults, we found a higher prevalence among females, a conclusion in agreement with results from other studies [25]. This is generally explained by hormonal differences playing a role in inflammatory conditions, smooth muscle and vascular functions [26, 27]. Also, obesity, which is associated with a higher risk of asthma symptoms [28], is very common among females in the UAE [29] and may, arguably, explain the higher prevalence of asthma in women in our study. Another unfavorable condition that is highly prevalent among Emirati women is hypovitaminosis D [20,30], a condition found to be associated with a higher risk of wheeze in 5-year-old offspring [18]. If this effect persists into adolescence or even adulthood, it could explain the higher prevalence among UAE nationals found in our study, both in adolescents and in adults. Although the effect of nationality was not significant among the adult group in the multivariate model, this was only due to the inclusion of family history of asthma in the model and therefore our conclusion that UAE nationals have a higher asthma risk is still valid. Family history was the strongest predictor of asthma among both age groups, a finding consistent with many other studies elsewhere in the world [31, 32].

The prevalence of asthma varies in different ethnic/ race groups [33, 34], and also depends on asthma care, compliance and counseling on environmental modifications among low-income populations [35]. However, these differences in reported asthma prevalence could be either reduced or eliminated after adjusting for risk factors such as socioeconomic status and urbanized lifestyle $[36,37]$. Presumably, the UAE nationals are, on average, urbanized with high household income as opposed to the other racial groups in this study. Therefore, whilst urbanized lifestyle and income may partially explain the strong association between asthma and UAE nationals, the current data possibly do not rule out the involvement of other possible confounding factors.

The current study reports not only the prevalence of asthma among children and adults in this population, but also highlights the multifactorial nature of asthma and its risk factors, which may contribute to our understanding, in the wider context, of the trends of asthma worldwide.

\section{Conclusion}

The prevalence of asthma found in this study is comparable to earlier reports in young age groups in the UAE as well as results from other Gulf States. The higher prevalence observed in adolescent males compared to females may possibly be due to sex-specific lifestyle factors or due to selection bias. Family history and UAE nationality were the strongest predictors of asthma in the population studied, presumably due to modernization and western lifestyle as well as possible genetic susceptibility. Further studies are required to investigate the possible role of specific risk factors of asthma in this population.

\section{Acknowledgment}

We gratefully acknowledge the generous financial support from the Faculty of Medicine and Health Sciences, UAE University.

\section{References}

1 The International Study of Asthma and Allergies in Childhood (ISAAC) Steering Committee. Worldwide variations in the prevalence of asthma symptoms: the International Study of Asthma and Allergies in Childhood (ISAAC). Eur Respir J 1998;12:315-335.

-2 European Community Respiratory Health Survey. Variations in the prevalence of respiratory symptoms, self-reported asthma attacks, and use of asthma medication in the European Community Respiratory Health Survey (ECRHS). Eur Respir J 1996;9:687695.
3 Moussa M, Skaik M, Yaghy O, Salwanes S, Bin-Othman S: Factors associated with asthma in school children. Eur J Epidemiol 1996; 12:583-588.

4 Host A, Halken S: The role of allergy in childhood asthma. Allergy 2000;55:600608.

5 Tariq S, Matthews S, Hakim E: The prevalence of and the risk factors for atopy in early childhood: a whole population birth cohort study. J Allergy Clin Immunol 1998;101: 587-593.
6 Wang T, Chiang W, Tseng H, Chu Y, Chen W, Shih N, Ko Y: The polymorphisms of Eotaxin 1 and CCR 3 genes influence on serum IgE, Eotaxin levels and mild asthmatic children in Taiwan. Allergy 2007;62:1125-1130.

7 Martin A, Mclennan L, Landau L, Phelan P: The natural history of childhood asthma to adult life. Br Med J 1980;280:1397-1400.

8 Kelly W, Hudson P, Phelan PD, Pain M, Olinsky A: Childhood asthma in adult life: a further study at 28 years of age. Br Med J (Clin Res Ed) 1987;294:1059-1062. 
$\checkmark 9$ Litonjua A, Weiss S: Is vitamin D deficiency to blame for the asthma epidemic? J Allergy Clin Immunol 2007;120:1031-1035.

10 Von Mutius E: Is asthma really linked to atopy? Clin Exp Allergy 2001;31:1651-1652.

- 11 Dong G, Ma Y, Ding H, Jing Jin J, Cao Yb, Zhao Yc, He Q: Effects of housing characteristics and home environmental factors on respiratory symptoms of 10,784 elementary school children from northeast China. Respiration 2008;76:82-91.

- 12 Priftis KN, Paliatsos AG, PanagiotopoulouGartagani P, Tapratzi-Potamianou P, Zachariadi-Xypolita A, Nicolaidou P, SaxoniPapageorgiou P: Association of weather conditions with childhood admissions for wheezy bronchitis or asthma in Athens. Respiration 2006;73:783-790.

13 Laitinen T: Gene mapping in asthma-related traits. Methods Mol Biol 2007;376:213-234.

-14 Sasser S, Gibbs M, Blackwell T: Prehospital emergency care in Abu Dhabi, United Arab Emirates. Prehosp Emerg Care 2004;8:5157.

-15 Bener A, Abdulrazzaq Y, Al-Mutawwa J, Debuse P: Genetic and environmental factors associated with asthma. Hum Biol 1996;68: 405-414.

-16 Bener A, Safa W, Abdulhalik S, Lestringant $\mathrm{G}$ : An analysis of skin prick test reactions in asthmatics in a hot climate and desert environment. Allerg Immunol (Paris) 2002;34: 281-286.

17 Lestringant G, Bener A, Frossard P, Abdulkhalik S, Bouix G: A clinical study of airborne allergens in the United Arab Emirates. Allerg Immunol (Paris) 1999;31:263-267.

-18 Devereux G, Litonjua A, Turner S, Craig L, McNeill G, Martindale S, Helms P, Seaton A, Weiss S: Maternal vitamin D intake during pregnancy and early childhood wheezing. Am J Clin Nutr 2007;85:853-859.

-19 Camargo C Jr, Rifas-Shiman S, Litonjua A, Rich-Edwards J, Weiss S, Gold D, Kleinman K, Gillman MW: Maternal intake of vitamin $\mathrm{D}$ during pregnancy and risk of recurrent wheeze in children at $3 \mathrm{y}$ of age. Am J Clin Nutr 2007;85:788-795.
20 Saadi H, Nagelkerke N, Qazaq H, Zilahi E, Mohamadiyeh M, Al-Suhaili A: Predictors and relationships of serum 25 hydroxyvitamin D concentration with bone turnover markers, bone mineral density, and vitamin D receptor genotype in Emirati women. Bone 2006;39:1136-1143.

21 Bener A, Abdulrazzaq Y, Debuse P, Al-Mutawwa J: Prevalence of asthma among Emirates school children. Eur J Epidemiol 1994; 10:271-278.

22 Al-Maskari F, Bener A, Al-Kaabi A, Al-Suwaidi N, Norman N, Brebner J: Asthma and respiratory symptoms among school children in United Arab Emirates. Allerg Immunol (Paris) 2000;32:159-163.

23 ISAAC Co-Ordinating Committee: Manual for the International Study of Asthma and Allergies in Childhood (ISAAC). Bochum/ Auckland, ISAAC Coordinating Committee, 1992.

24 Al-Riyami BM, Al-Rawas OA, Al-Riyami AA, Jasim LG, Mohammed AJ: A relatively high prevalence and severity of asthma, allergic rhinitis and atopic eczema in schoolchildren in the Sultanate of Oman. Respirology 2003;8:69-76.

25 Almqvist C, Worm M, Leynaert B, Working Group of GA2LEN WP 2.5 Gender: Impact of gender on asthma in childhood and adolescence: a GA2LEN review. Allergy 2008; 63:47-57.

26 Von Mutius E: Progression of allergy and asthma through childhood to adolescence. Thorax 1996;51:S3-S6.

27 Becklake MR, Kauffmann F: Gender differences in airway behaviour over the human life span. Thorax 1999;54:1119-1138.

28 Corbo GM, Forastiere F, De Sario M, Brunetti L, Bonci E, Bugiani M, Chellini E, La Grutta S, Migliore E, Pistelli R, Rusconi F, Russo A, Simoni M, Talassi F, Galassi C, Sidria-2 Collaborative Group: Wheeze and asthma in children: associations with body mass index, sports, television viewing, and diet. Epidemiology 2008;19:747-755.
29 Malik M, Bakir A: Prevalence of overweight and obesity among children in the United Arab Emirates. Obes Rev 2007;8:15-20.

$\checkmark 30$ Dawodu A, Dawson KP, Amirlak I, Kochiyil J, Agarwal M, Badrinath P: Diet, clothing, sunshine exposure and micronutrient status of Arab infants and young children. Ann Trop Paediatr 2001;21:39-44.

-31 Burke W, Fesinmeyer M, Reed K, Hampson L, Carlsten C: Family history as a predictor of asthma risk. Am J Prev Med 2003;24:160169.

32 Liebhart J, Malolepszy J, Wojtyniak B, Pisiewicz K, Plusa T, Gladysz U, Polish Multicentre Study of Epidemiology of Allergic Diseases: Prevalence and risk factors for asthma in Poland: results from the PMSEAD study. J Investig Allergol Clin Immunol 2007;17: 367-374.

33 Gergen PJ, Mullally DI, Evans R III: National survey of prevalence of asthma among children in the United States, 1976 to 1980. Pediatrics 1988;81:1-7.

-34 Schwartz J, Gold D, Dockery DW, Weiss ST, Speizer FE: Predictors of asthma and persistent wheeze in a national sample of children in the United States. Association with social class, perinatal events, and race. Am Rev Respir Dis 1990;142:555-562.

-35 Inkelas M, Garro N, McQuaid EL, Ortega AN: Race/ethnicity, language, and asthma care: findings from a 4-state survey. Ann Allergy Asthma Immunol 2008;100:120-127.

-36 Aligne CA, Auinger P, Byrd RS, Weitzman $\mathrm{M}$ : Risk factors for pediatric asthma. Contributions of poverty, race, and urban residence. Am J Respir Crit Care Med 2000;162: 873-877.

37 Litonjua AA, Carey VJ, Weiss ST, Gold DR: Race, socioeconomic factors, and area of residence are associated with asthma prevalence. Pediatr Pulmonol 1999;28:394-401. 